\title{
ENVELHECIMENTO ACELERADO E DETERIORAÇÃO CONTROLADA EM SEMENTES DE TOMATE
}

\author{
Maristela Panobianco ${ }^{1,3 *}$; Júlio Marcos Filho ${ }^{2,3}$

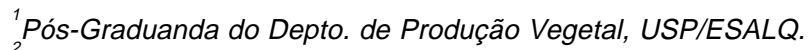 \\ ${ }_{3}^{2}$ Depto. de Produção Vegetal, USP/ESALQ, C.P. 9 - CEP: 13418-900 - Piracicaba, SP. \\ ${ }^{3}$ Bolsista CNPq. \\ *Autor correspondente <mapanobianco@uol.com.br>
}

RESUMO: Sementes de tomate apresentam alto valor comercial e, por esse motivo, merecem atenção especial quanto ao potencial fisiológico, principalmente devido às dificuldades para o armazenamento; para tanto, estudos dirigidos à determinação do vigor devem ser utilizados e intensificados. Este trabalho teve por objetivo estudar o envelhecimento acelerado e a deterioração controlada para avaliação do potencial fisiológico de sementes de tomate. Para tanto, cinco lotes de sementes, dos híbridos Debora Plus e Bruna, foram submetidos aos testes de germinação, emergência das plântulas em casa de vegetação, envelhecimento acelerado (empregando-se os períodos de 48 e 72 horas, a $38^{\circ} \mathrm{C}$ ou $41^{\circ} \mathrm{C}$, com e sem o uso de solução saturada de $\mathrm{NaCl}$ ) e deterioração controlada (sementes com graus de umidade de 19\%, 21\% e 24\%, a $45^{\circ} \mathrm{C}$, durante 24 e 48 horas). A combinação $72 \mathrm{~h} / 41^{\circ} \mathrm{C} / \mathrm{com}$ ou sem o uso da solução saturada de $\mathrm{NaCl}$, no teste de envelhecimento acelerado, e a combinação $24 \%$ de água $/ 24 \mathrm{~h} / 45^{\circ} \mathrm{C}$, no teste de deterioração controlada, são eficientes para detectar diferenças de vigor entre os lotes de sementes de tomate.

Palavras-chave: Lycopersicon lycopersicum, vigor, potencial fisiológico, geminação

\section{ACCELERATED AGING AND CONTROLLED DETERIORATION OF TOMATO SEEDS}

\begin{abstract}
Tomato seeds have a high commercial value, and the loss of seed physiological quality over time is demonstrated by their low storability unless hermetic conditions are used. As a result the development of satisfactory seed vigor test must be used and intensified. The objective of the present work was to study the accelerated aging and the controlled deterioration to evaluate the physiological quality of tomato seeds. Five seed lots of hybrids Debora Plus and Bruna were submitted to tests of germination, seedling emergence, accelerated aging (periods of 48 and 72 hours, at $38^{\circ} \mathrm{C}$ or $41^{\circ} \mathrm{C}$, with or without the use of saturated solution of $\mathrm{NaCl}$ ) and controlled deterioration ( $19 \%, 21 \%$ and $24 \%$ water content, at $45^{\circ} \mathrm{C}$ and 24 - and 48 -hour periods). Among the adopted procedures the $72 \mathrm{~h} / 41^{\circ} \mathrm{C} /$ with or without the use of saturated solution of $\mathrm{NaCl}$ combination, for the accelerated aging test, and the $24 \%$ water $/ 24 \mathrm{~h} / 45^{\circ} \mathrm{C}$ combination, for the controlled deterioration test, are efficient to detect vigor differences among tomato seed lots.
\end{abstract}

Key words: Lycopersicon lycopersicum, vigor, physiological quality, germination

\section{INTRODUÇÃO}

O objetivo básico dos testes de vigor é a identificação de diferenças importantes no potencial fisiológico das sementes, principalmente das que compõem lotes com poder germinativo elevado e semelhante (Marcos Filho, 1999a). Freqüentemente, observa-se que lotes de sementes apresentando germinação semelhante exibem comportamentos distintos no campo e/ou armazenamento.

Essas diferenças podem ser explicadas pelo fato de que as primeiras alterações nos processos bioquímicos associados à deterioração ocorrem, geralmente, antes que sejam verificados declínios na capacidade germinativa (Delouche \& Baskin, 1973). Por este motivo, o uso de testes de vigor é de grande utilidade no monitoramento da qualidade das sementes, a partir da maturidade.

No entanto, poucos estudos têm sido conduzidos sobre o uso de testes de vigor para avaliação do potencial fisiológico de sementes de hortaliças. Segundo Marcos Filho (1999a), as informações sobre o vigor são ainda mais importantes para sementes de maior valor comercial, como as hortaliças; estas, em razão de apresentarem menores quantidades de reservas armazenadas, possuem maior propensão à deterioração após a maturidade fisiológica. Tanto assim, que são habitualmente armazenadas em embalagens herméticas ou em ambientes especiais, sob temperatura e/ou umidade relativa reduzidas.

O tomate, dentre as hortaliças, é produzido em volumes significativos. As sementes, por apresentarem alto valor comercial e, ainda, pela forma de comercialização (embalagens impermeáveis), merecem atenção especial quanto ao seu potencial fisiológico; para tanto, testes dirigidos à determinação do vigor devem ser utilizados e intensificados. Todavia, também para esta espécie, a pesquisa não tem oferecido alternativas suficientes, especialmente quando se considera a importância da obtenção relativamente rápida das informações. 
Dentre os testes utilizados para avaliação do vigor, o envelhecimento acelerado é um dos mais estudados e recomendados para várias espécies cultivadas. Este teste tem como princípio o aumento considerável da taxa de deterioração das sementes através de sua exposição a níveis elevados de temperatura e umidade relativa do ar, considerados os fatores ambientais preponderantes na intensidade e velocidade de deterioração (Marcos Filho, 1999b). Assim, sementes de baixa qualidade deterioram-se mais rapidamente do que as mais vigorosas, apresentando queda acentuada de sua viabilidade, após serem submetidas ao envelhecimento acelerado.

De acordo com a seqüência hipotética proposta por Delouche \& Baskin (1973), a redução do potencial de armazenamento é a primeira manifestação fisiológica da deterioração, após o decréscimo da velocidade de germinação. Consequentemente, 0 teste de envelhecimento acelerado pode ser considerado como um dos mais sensíveis para avaliação do vigor, dentre os disponíveis (Marcos Filho, 1999b).

As diferenças na absorção de água pelas sementes, a partir da atmosfera úmida, podem originar, entretanto, variações acentuadas no grau de umidade das amostras. Pesquisas conduzidas com espécies de sementes de menor tamanho, como as hortaliças, têm revelado resultados pouco consistentes para esse teste (Powell, 1995). Por esse motivo, vêm sendo estudadas alternativas para a condução do envelhecimento acelerado em espécies de sementes pequenas, como a substituição da água por soluções saturadas de sal. Dependendo da solução utilizada, são obtidos níveis específicos de umidade relativa do ar, permitindo adequar a taxa de absorção de água da semente à velocidade e à intensidade de deterioração da mesma (Jianhua \& McDonald, 1996). Nesse sentido, tem sido observada maior eficiência do teste de envelhecimento acelerado com uso de soluções saturadas de sal na classificação de lotes de sementes com diferentes níveis de vigor em milho doce (Bennett et al., 1998), pimentão (Panobianco \& Marcos Filho, 1998) e cenoura (Rodo et al., 2000).

Por outro lado, diferenças no vigor de lotes de sementes também têm sido detectadas pelo teste de deterioração controlada, cujo princípio é equivalente ao do envelhecimento acelerado. No entanto, a avaliação é efetuada em amostras com teores de água semelhantes, em vez da utilização de ambientes com alta umidade relativa do ar, resultando na obtenção de condições mais uniformes durante o teste e, consequentemente, padronização mais efetiva, principalmente em espécies que produzem sementes de menor tamanho.

De acordo com o princípio do teste, o envelhecimento mais rápido de sementes ocorre quando as mesmas são armazenadas sob condições de elevado teor de água e alta temperatura (Powell, 1995). A comparação da resposta de vários lotes seria possível através de um controle preciso da temperatura e do teor de água das sementes, de modo que o mesmo grau de envelhecimento ou deterioração seria imposto de maneira uniforme a todos os lotes. A mesma autora ponderou que, no teste de envelhecimento acelerado, as diferenças na absorção de água, a partir da atmosfera úmida, geralmente determinam variações acentuadas no grau de umidade das amostras, o que não tem ocorrido no teste de deterioração controlada, especialmente para espécies de sementes pequenas.

Diante do exposto, o presente trabalho teve por objetivo estudar a metodologia dos testes de envelhecimento acelerado e de deterioração controlada para avaliação do potencial fisiológico de sementes de tomate.

\section{MATERIAL E MÉTODOS}

O trabalho foi realizado no Laboratório de Análise de Sementes e no Campo Experimental do Departamento de Produção Vegetal da Escola Superior de Agricultura "Luiz de Queiroz", em Piracicaba, SP, nos meses de fevereiro a junho de 1999.

Foram utilizadas sementes de tomate, dos híbridos Debora Plus e Bruna (grupo Santa Cruz), cada um representado por cinco lotes. As sementes foram submetidas aos testes descritos a seguir.

a) Determinação do grau de umidade - Efetuada em estufa a $105 \pm 3^{\circ} \mathrm{C}$, durante 24 horas, segundo as instruções das Regras para Análise de Sementes (Brasil, 1992), utilizando-se duas amostras para cada lote, com aproximadamente $2,0 \mathrm{~g}$ de sementes cada. Os resultados foram expressos em percentagem média para cada lote.

b) Germinação - Utilizaram-se três repetições de 50 sementes para cada lote, colocadas para germinar sobre duas folhas de papel mata-borrão (tipo Germibox) umedecidas com quantidade de água equivalente a 2,5 vezes o peso do substrato, no interior de caixas plásticas $(11,0 \times 11,0 \times 3,5 \mathrm{~cm})$, a $25^{\circ} \mathrm{C}$. As avaliações foram realizadas aos sete e 14 dias após a semeadura, segundo os critérios estabelecidos pelas Regras para Análise de Sementes (Brasil, 1992), computando-se a percentagem de plântulas normais.

c) Emergência de plântulas em casa de vegetação Foram utilizadas quatro repetições de 50 sementes semeadas em bandejas de poliestireno ("isopor") com células individuais, contendo substrato comercial obtido pela mistura de casca de pinus, vermiculita e fertilizante químico (informações fornecidas pelo fabricante). As bandejas foram mantidas a $25^{\circ} \mathrm{C}$, em estufa dotada de sistema de nebulização intermitente. As avaliações foram realizadas aos 14 dias após a semeadura, através da contagem de plântulas normais emergidas com tamanho igual ou superior a $1,0 \mathrm{~cm}$. 
d) Envelhecimento acelerado (procedimento tradicional) - Conduzido com a utilização de caixas plásticas $(11,0 \times 11,0 \times 3,5 \mathrm{~cm})$ como compartimento individual (mini-câmaras), possuindo em seu interior uma bandeja de tela de alumínio, onde as sementes, após pesagem (aproximadamente 3,0 g), foram distribuídas de maneira a formarem camada simples sobre a superfície da tela; no interior de cada caixa foram adicionados $40 \mathrm{~mL}$ de água. As caixas, tampadas, foram mantidas em incubadora por dois períodos de envelhecimento $(48 \mathrm{~h}$ e $72 \mathrm{~h})$, sendo utilizadas duas temperaturas $\left(38^{\circ} \mathrm{C}\right.$ e $41^{\circ} \mathrm{C}$ ). Decorrido cada período de envelhecimento, três amostras de 50 sementes por tratamento foram colocadas para germinar conforme metodologia descrita para o teste de germinação. A avaliação foi realizada aos sete dias após a semeadura, computando-se a percentagem de plântulas normais. Foi determinado, também, o grau de umidade das sementes antes e após o período de envelhecimento, visando avaliação da uniformidade das condições do teste.

e) Envelhecimento acelerado (solução saturada de sal) - Conduzido de modo semelhante ao descrito para o estudo sobre o teste tradicional, adicionando-se, porém, ao fundo de cada caixa plástica, $40 \mathrm{~mL}$ de solução saturada de $\mathrm{NaCl}$, em vez de $40 \mathrm{~mL}$ de água, proporcionando ambiente com $76 \%$ de UR.

f) Deterioração controlada - Inicialmente, o grau de umidade das sementes foi ajustado para três níveis diferentes $(19 \%, 21 \%$ e $24 \%)$, através do método da atmosfera úmida (Rossetto et al., 1995), conduzido em caixas plásticas (11,0 x 11,0 × 3,5 cm), com amostras de $3,0 \mathrm{~g}$ de sementes, colocadas sobre a tela interna mediante a distribuição de uma camada simples. Estas caixas, tampadas e contendo $40 \mathrm{~mL}$ de água, foram mantidas em incubadora, a $20^{\circ} \mathrm{C}$. Durante 0 umedecimento artificial, o grau de umidade das sementes foi monitorado, através de pesagens sucessivas, até a obtenção dos valores desejados; nesta ocasião, cada amostra foi colocada em recipiente de folha de alumínio, fechado hermeticamente, permanecendo por cinco dias em câmara fria $\left(8-10^{\circ} \mathrm{C}\right)$ para atingir o equilíbrio higroscópico. Em seguida, as sementes foram mantidas em banho-maria, a $45^{\circ} \mathrm{C}$, durante dois períodos $(24 \mathrm{~h}$ e $48 \mathrm{~h})$. Posteriormente, os recipientes foram imersos rapidamente em água fria para reduzir a temperatura, sendo instalado em seguida o teste de germinação (Powell, 1995); as interpretações do teste foram efetuadas aos sete dias após a semeadura, computandose as percentagens de plântulas normais. Foi determinado, também, o grau de umidade das sementes após cada período de deterioração.

g) Procedimento estatístico - para cada híbrido, utilizouse delineamento estatístico inteiramente casualizado, com três repetições estatísticas, com exceção da emergência de plântulas em casa de vegetação, conduzida com quatro repetições. As médias obtidas nas avaliações de cada lote foram comparadas pelo teste de Tukey, a 5\%. Para execução das análises estatísticas foi utilizado o "Sistema de Análise Estatística para Microcomputadores - SANEST" (Zonta \& Machado, 1984). Os dados dos testes foram transformados em arc $\operatorname{sen} \sqrt{x / 100}$.

\section{RESULTADOS E DISCUSSÃO}

\section{Híbrido Debora Plus}

Na TABELA 1, estão apresentados os resultados do grau de umidade, germinação e emergência de plântulas em casa de vegetação, híbrido Debora Plus.

Verificou-se pelo teste de germinação que houve melhor desempenho dos lotes 1 e 2, em relação aos lotes 3,4 e 5 . Pelos resultados de emergência de plântulas em casa de vegetação pode-se notar que os lotes 1 e 2, não diferentes entre si, foram superiores aos lotes 4 e 5; em contrapartida, o lote 4 apresentou menor percentagem de emergência, não diferindo significativamente do lote 5 , enquanto que para o lote 3 foi encontrado valor intermediário. Vale ainda ressaltar, que a percentagem de germinação de um modo geral superou a de emergência das plântulas; isto já esperado, visto que o teste de germinação é conduzido sob condições ótimas.

Os dados referentes ao grau de umidade das sementes (TABELA 1) foram semelhantes para os cinco lotes estudados; este fato é importante na execução dos testes, uma vez que a uniformização do grau de umidade das sementes é fundamental para a padronização das avaliações e obtenção de resultados consistentes (Marcos Filho et al., 1987; Loeffler et al., 1988).

Os resultados do teste de envelhecimento acelerado (procedimento tradicional e com solução salina), híbrido Debora Plus, utilizando-se duas temperaturas e dois períodos de condicionamento, estão apresentados na TABELA 2.

No procedimento tradicional, pode-se verificar que o período de 72 horas, a $41^{\circ} \mathrm{C}$, mostrou maior concordância com os resultados dos testes de germinação e emergência em casa de vegetação (TABELA 1), revelando o melhor desempenho dos lotes 1 e 2 em relação aos demais.

Com relação à condução do teste de envelhecimento acelerado com o uso de solução salina, observou-se que o período de 72 horas, tanto a $38^{\circ} \mathrm{C}$ quanto a $41^{\circ} \mathrm{C}$, forneceu informações mais compatíveis com os testes de germinação e emergência de plântulas quanto à classificação dos lotes em níveis de vigor, destacando o melhor desempenho do lote 1 e a qualidade inferior dos lotes 4 e 5 ; os lotes 2 e 3 foram identificados como de nível intermediário, porém, com tendência de inferioridade para o lote 3 . A descrição do teste de envelhecimento cita a possibilidade da utilização de temperaturas de 40 a $45^{\circ} \mathrm{C}$; mais recentemente, grande parte dos pesquisadores que se dedicam a estudos sobre o teste indicam o uso de $41^{\circ} \mathrm{C}$ (Marcos 
Filho, 1999b). Dessa forma, pode-se considerar como mais adequada a combinação de $41^{\circ} \mathrm{C} / 72$ horas de condicionamento para a condução do teste de envelhecimento acelerado, com 0 uso de solução saturada de sal, híbrido Debora Plus.

Os dados referentes ao grau de umidade das sementes após os períodos de condicionamento (tradicional e com solução salina) encontram-se na TABELA 3. No procedimento tradicional, houve variação entre os lotes de 1,3 a $3,7 \%$, dependendo da combinação período / temperatura utilizada. O maior valor foi sempre encontrado para o lote 1 , confirmando a tendência observada para o mesmo lote, antes da realização dos testes (TABELA 1). Deve-se ressaltar, também, que as sementes do lote 1 possuíam grau de umidade mais elevado, porém as metodologias de envelhecimento acelerado estudadas identificaram o lote 1 como o mais vigoroso; portanto, essa pequena diferença inicial no grau de umidade não foi suficiente para mascarar os resultados obtidos.

Por outro lado, as sementes expostas à solução saturada do sal apresentaram valores menores e mais uniformes de grau de umidade, após os períodos de envelhecimento, do que os observados para as

TABELA 1 - Grau de umidade, germinação e emergência em casa de vegetação de sementes de cinco lotes de tomate, híbrido Debora Plus.

\begin{tabular}{|c|c|c|c|}
\hline $\begin{array}{c}\text { Hibrido } \\
\text { Debora Plus }\end{array}$ & $\begin{array}{l}\text { Grau de } \\
\text { umidade }\end{array}$ & Germinação & $\begin{array}{l}\text { Emergência } \\
\text { de Plântula }\end{array}$ \\
\hline Lote & --.-- & --- \% ----- & - \\
\hline 1 & 8,6 & $97 \mathrm{a}^{*}$ & $97 a$ \\
\hline 2 & 8,1 & $97 \mathrm{a}$ & $92 \mathrm{ab}$ \\
\hline 3 & 8,3 & $88 \mathrm{~b}$ & $86 b c$ \\
\hline 4 & 8,4 & $85 b$ & $73 d$ \\
\hline 5 & 8,4 & $86 \mathrm{~b}$ & $80 \mathrm{~cd}$ \\
\hline C.V. (\%) & - & 3,42 & 5,26 \\
\hline
\end{tabular}

${ }^{\star}$ Comparação de médias em cada coluna, pelo teste de Tukey a $5 \%$. envelhecidas sem o uso de solução salina, revelando que o método conseguiu retardar a absorção de água das sementes no teste de envelhecimento acelerado. Assim, é possível supor que as condições de envelhecimento com 0 uso de solução salina promoveriam efeitos menos drásticos, pois ao atingir menores teores de água, o grau de deterioração das sementes seria atenuado em relação ao normalmente verificado com o uso do método tradicional. Os resultados obtidos até o momento, com o teste, demonstraram que mesmo com grau de umidade baixo, há estresse (Jianhua \& McDonald, 1996; Panobianco \& Marcos Filho, 1998; Rodo et al., 2000).

Uma vantagem da utilização de soluções saturadas de sais é que os valores de umidade relativa permanecem em níveis inferiores, suficientes para impedir o crescimento de microrganismos, minimizando, assim, a preocupação com efeitos de patógenos associados às sementes sobre os resultados do teste de envelhecimento acelerado (Jianhua \& McDonald, 1996).

Examinando os dados obtidos no teste de deterioração controlada (TABELA 4), observou-se que a combinação 24h / 24\% mostrou tendência compatível com a ordenação dos lotes obtida pelo teste de emergência em casa de vegetação, sendo considerada mais promissora. Assim, classificou, de maneira geral, os lotes 1 e 2 como superiores; os lotes 4 e 5 como inferiores e, o lote 3 , como de qualidade intermediária, porém, tendendo para inferioridade.

Com relação aos dados referentes ao grau de umidade das sementes após o período em banho-maria, no teste de deterioração controlada (TABELA 4), podese observar que as sementes permaneceram, praticamente, com os mesmos graus de umidade em relação ao início do teste. Assim, a técnica utilizada para a deterioração controlada mostrou-se eficiente, no sentido de manter constante o grau de umidade das sementes durante o decorrer do teste.

TABELA 2 - Dados médios obtidos para o teste de envelhecimento acelerado (procedimento tradicional e com solução salina) de sementes de cinco lotes de tomate, híbrido Debora Plus.

\begin{tabular}{|c|c|c|c|c|c|c|c|c|}
\hline \multirow[t]{3}{*}{$\begin{array}{c}\text { Hibrido } \\
\text { Debora Plus }\end{array}$} & \multicolumn{4}{|c|}{$\begin{array}{l}\text { Envelhecimento acelerado } \\
\text { (tradicional) }\end{array}$} & \multicolumn{4}{|c|}{$\begin{array}{l}\text { Envelhecimento acelerado } \\
\text { (com solução salina) }\end{array}$} \\
\hline & \multicolumn{2}{|c|}{$38^{\circ} \mathrm{C}$} & \multicolumn{2}{|c|}{$41^{\circ} \mathrm{C}$} & \multicolumn{2}{|c|}{$38^{\circ} \mathrm{C}$} & \multicolumn{2}{|c|}{$41^{\circ} \mathrm{C}$} \\
\hline & $48 \mathrm{~h}$ & $72 \mathrm{~h}$ & $48 \mathrm{~h}$ & $72 \mathrm{~h}$ & $48 \mathrm{~h}$ & $72 \mathrm{~h}$ & $48 \mathrm{~h}$ & $72 \mathrm{~h}$ \\
\hline Lote & \multicolumn{8}{|c|}{ 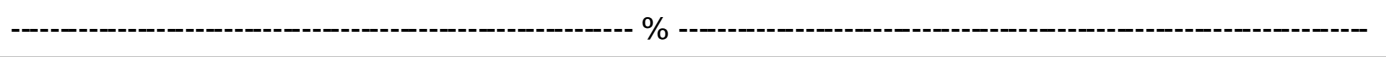 } \\
\hline 1 & $90 a^{*}$ & $87 \mathrm{a}$ & $84 \mathrm{ab}$ & $88 \mathrm{a}$ & $95 \mathrm{a}$ & 96 a & $94 a^{*}$ & $94 \mathrm{a}$ \\
\hline 2 & $82 a b$ & $87 \mathrm{a}$ & $84 \mathrm{ab}$ & $83 a b$ & $93 \mathrm{a}$ & $87 b$ & $96 a$ & $85 b$ \\
\hline 3 & $83 a b$ & $88 a$ & $90 \mathrm{a}$ & $75 \mathrm{bc}$ & $87 a b$ & $78 \mathrm{bc}$ & $92 a b$ & 76 bc \\
\hline 4 & $78 \mathrm{~b}$ & $65 b$ & $63 c$ & $70 \mathrm{c}$ & $78 \mathrm{~b}$ & $67 c$ & $80 \mathrm{c}$ & $63 c$ \\
\hline 5 & $78 \mathrm{~b}$ & $68 \mathrm{~b}$ & $78 \mathrm{~b}$ & $73 \mathrm{bc}$ & $83 \mathrm{~b}$ & $75 c$ & $85 \mathrm{bc}$ & $70 \mathrm{c}$ \\
\hline C.V.(\%) & \multicolumn{4}{|c|}{5,07} & \multicolumn{4}{|c|}{5,59} \\
\hline
\end{tabular}

${ }^{*}$ Comparação de médias em cada coluna, pelo teste de Tukey a $5 \%$. 
TABELA 3 - Dados médios de grau de umidade obtidos após os períodos de envelhecimento acelerado (procedimento tradicional e com solução salina) de sementes de cinco lotes de tomate, híbrido Debora Plus.

\begin{tabular}{|c|c|c|c|c|c|c|c|c|}
\hline \multirow[t]{3}{*}{$\begin{array}{c}\text { Hîbrido Debora } \\
\text { Plus }\end{array}$} & \multicolumn{4}{|c|}{$\begin{array}{l}\text { Grau de umidade após } \\
\text { envelhecimento acelerado } \\
\text { (tradicional) }\end{array}$} & \multicolumn{4}{|c|}{$\begin{array}{c}\text { Grau de umidade após enve lhecimento } \\
\text { acelerado } \\
\text { (com solução salina) }\end{array}$} \\
\hline & \multicolumn{2}{|c|}{$38^{\circ} \mathrm{C}$} & \multicolumn{2}{|c|}{$41^{\circ} \mathrm{C}$} & \multicolumn{2}{|c|}{$38^{\circ} \mathrm{C}$} & \multicolumn{2}{|c|}{$41^{\circ} \mathrm{C}$} \\
\hline & $48 \mathrm{~h}$ & $72 \mathrm{~h}$ & $48 \mathrm{~h}$ & $72 \mathrm{~h}$ & $48 \mathrm{~h}$ & $72 \mathrm{~h}$ & $48 \mathrm{~h}$ & $72 \mathrm{~h}$ \\
\hline Lote & --------- & ----- & ----- & ---- \% & ---- & ----- & ------ & ------- \\
\hline 1 & 38,5 & 39,4 & 40,3 & 41,0 & 9,8 & 10,4 & 10,0 & 10,6 \\
\hline 2 & 35,9 & 36,1 & 36,9 & 37,3 & 9,0 & 9,3 & 9,7 & 9,8 \\
\hline 3 & 36,9 & 37,2 & 37,1 & 38,3 & 9,4 & 9,7 & 9,9 & 9,8 \\
\hline 4 & 37,4 & 38,0 & 38,1 & 39,5 & 9,7 & 10,2 & 9,8 & 10,3 \\
\hline 5 & 37,1 & 37,6 & 38,1 & 38,3 & 9,6 & 9,8 & 9,6 & 10,1 \\
\hline
\end{tabular}

TABELA 4 - Dados médios obtidos para o teste de deterioração controlada e para o grau de umidade após os períodos de condicionamento, de sementes de cinco lotes de tomate, híbrido Debora Plus.

\begin{tabular}{|c|c|c|c|c|c|c|c|c|c|c|c|c|}
\hline \multirow{3}{*}{$\begin{array}{c}\text { Hibrido } \\
\text { Debora Plus }\end{array}$} & \multicolumn{6}{|c|}{ Deterioração controlada } & \multicolumn{6}{|c|}{ Grau de umidade após deterioração controlada } \\
\hline & \multicolumn{3}{|c|}{$24 \mathrm{~h}$} & \multicolumn{3}{|c|}{$48 \mathrm{~h}$} & \multicolumn{3}{|c|}{$24 \mathrm{~h}$} & \multicolumn{3}{|c|}{$48 \mathrm{~h}$} \\
\hline & $19 \%$ & $21 \%$ & $24 \%$ & $19 \%$ & $21 \%$ & $24 \%$ & $19 \%$ & $21 \%$ & $24 \%$ & $19 \%$ & $21 \%$ & $24 \%$ \\
\hline Lote & ------- & ----- & ------. & ------ & - & $-\%$ & - & --- & --- & ----- & 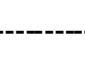 & - \\
\hline 1 & $93 a^{*}$ & $96 \mathrm{a}$ & $89 a$ & $96 \mathrm{a}$ & $92 a b$ & $86 \mathrm{a}$ & 18,9 & 20,8 & 24,2 & 18,7 & 21,0 & 23,7 \\
\hline 2 & $86 \mathrm{~b}$ & $80 \mathrm{~b}$ & $91 \mathrm{a}$ & $80 \mathrm{~b}$ & $86 \mathrm{a}$ & $91 \mathrm{a}$ & 19,4 & 20,7 & 23,8 & 19,0 & 20,7 & 24,1 \\
\hline 3 & $83 \mathrm{bc}$ & $91 \mathrm{a}$ & $83 \mathrm{bc}$ & $95 \mathrm{a}$ & 73 bc & $88 \mathrm{a}$ & 18,6 & 20,7 & 23,7 & 19,2 & 20,9 & 24,1 \\
\hline 4 & $67 d$ & $76 \mathrm{~b}$ & $70 d$ & $55 \mathrm{c}$ & $67 c$ & $65 \mathrm{~b}$ & 18,7 & 20,8 & 23,7 & 19,4 & 20,6 & 23,8 \\
\hline 5 & $73 \mathrm{~cd}$ & $81 \mathrm{~b}$ & $79 \mathrm{~cd}$ & $87 \mathrm{~b}$ & $73 \mathrm{bc}$ & $73 \mathrm{~b}$ & 18,7 & 21,1 & 24,2 & 19,5 & 20,7 & 24,4 \\
\hline
\end{tabular}

${ }^{*}$ Comparação de médias em cada coluna, pelo teste de Tukey a $5 \%$.

\section{Híbrido Bruna}

Os dados obtidos para grau de umidade, germinação e emergência em casa de vegetação, híbrido Bruna, encontram-se na TABELA 5.

$O$ grau de umidade das sementes foi semelhante para todos os lotes, da mesma maneira relatada para 0 híbrido Debora Plus. Pelo teste de germinação, o lote 1 mostrou-se superior, apesar de estatisticamente semelhante aos lotes 2 e 4, que não diferiram do lote 5; este, por sua vez, foi significativamente semelhante ao lote 3 , de poder germinativo mais baixo. O teste de emergência em casa de vegetação promoveu separação semelhante ao de germinação: os lotes 1 e 4 revelaramse como os de melhor qualidade, apesar de estatisticamente semelhantes ao lote 2, o qual não diferiu do lote 5; este, por sua vez, foi significativamente semelhante ao lote 3 , revelado como o de pior desempenho. Vale destacar que, também para o híbrido Bruna, o teste de germinação apresentou maior percentagem de plântulas normais que o de emergência.
Os resultados do teste de envelhecimento acelerado (procedimento tradicional e com solução salina), híbrido Bruna, utilizando-se duas temperaturas e dois períodos de condicionamento, estão apresentados na TABELA 6.

A análise dos resultados obtidos, pelo procedimento tradicional, indicou que o período de 72 horas, a $41^{\circ} \mathrm{C}$, mostrou-se mais relacionado com os testes de germinação e emergência de plântulas em casa de vegetação (TABELA 5), especialmente quanto à identificação de lotes de potencial fisiológico elevado.

Com relação ao procedimento alternativo (solução salina), verificou-se que o período de 72 horas de condicionamento, tanto a $38^{\circ} \mathrm{C}$ quanto a $41^{\circ} \mathrm{C}$, foi o mais eficiente quanto à ordenação de lotes em diferentes níveis de vigor, estando de acordo com o resultados fornecidos pelos testes de germinação e emergência. Em razão do uso mais freqüente da temperatura de $41^{\circ} \mathrm{C}$ para realização do teste de envelhecimento acelerado, 
considerou-se como mais adequada a combinação $41^{\circ} \mathrm{C} /$ 72 horas de condicionamento.

Os dados referentes ao grau de umidade das sementes após os períodos de condicionamento (tradicional e com solução salina) encontram-se na TABELA 7. No procedimento tradicional, os valores foram semelhantes para os cinco lotes estudados, com uma variação de 1,7 a 2,4\%, dependendo da metodologia estudada. Por outro lado, as sementes expostas à solução saturada do sal apresentaram valores menores e mais uniformes do que os observados para as envelhecidas com o uso do método tradicional.

Com relação ao teste de deterioração controlada (TABELA 8), assim como observado para o híbrido Debora Plus, a combinação $24 \mathrm{~h} / 24 \%$ mostrou-se mais compatível com os resultados obtidos nos testes de germinação e emergência de plântulas em casa de vegetação (TABELA 5) quanto à separação dos lotes em níveis de vigor; por esse motivo, foi considerada como mais promissora, revelando a superioridade dos lotes 1 , 2 e 4 e o pior desempenho do lote 3 .
Examinando o grau de umidade das sementes, após os períodos em banho-maria (TABELA 8), podese observar que a técnica empregada para realização da deterioração controlada foi eficiente, mantendo aproximadamente constantes os graus de umidade das sementes durante o decorrer do teste.

TABELA 5 - Valores médios de grau de umidade, germinação e emergência em casa de vegetação de sementes de cinco lotes de tomate, híbrido Bruna.

\begin{tabular}{cccc}
\hline $\begin{array}{c}\text { Hibrido } \\
\text { Bruna }\end{array}$ & $\begin{array}{c}\text { Grau de } \\
\text { umidade }\end{array}$ & Germinação & $\begin{array}{c}\text { Emergência } \\
\text { de Plântula }\end{array}$ \\
\hline Lote & $-0 .---1$ & \% \\
1 & 8,4 & $97 \mathrm{a}^{*}$ & $94 \mathrm{a}$ \\
2 & 8,2 & $94 \mathrm{ab}$ & $89 \mathrm{ab}$ \\
3 & 8,2 & $85 \mathrm{c}$ & $76 \mathrm{c}$ \\
4 & 8,3 & $94 \mathrm{ab}$ & $93 \mathrm{a}$ \\
5 & 8,3 & $88 \mathrm{bc}$ & $78 \mathrm{bc}$ \\
\hline C.V. (\%) & - & 3,60 & 5,95 \\
\hline
\end{tabular}

${ }^{*}$ Comparação de médias em cada coluna, pelo teste de Tukey a $5 \%$.

TABELA 6 - Dados médios obtidos para o teste de envelhecimento acelerado (procedimento tradicional e com solução salina) de sementes de cinco lotes de tomate, híbrido Bruna.

\begin{tabular}{|c|c|c|c|c|c|c|c|c|}
\hline \multirow[t]{3}{*}{$\begin{array}{l}\text { Hîbrido } \\
\text { Bruna }\end{array}$} & \multicolumn{4}{|c|}{ Envelhecimento acelerado (tradicional) } & \multicolumn{4}{|c|}{$\begin{array}{c}\text { Envelhecimento acelerado } \\
\text { (com solução salina) }\end{array}$} \\
\hline & \multicolumn{2}{|c|}{$38^{\circ} \mathrm{C}$} & \multicolumn{2}{|c|}{$41^{\circ} \mathrm{C}$} & \multicolumn{2}{|c|}{$38^{\circ} \mathrm{C}$} & \multicolumn{2}{|c|}{$41^{\circ} \mathrm{C}$} \\
\hline & $48 \mathrm{~h}$ & $72 \mathrm{~h}$ & $48 \mathrm{~h}$ & $72 \mathrm{~h}$ & $48 \mathrm{~h}$ & $72 \mathrm{~h}$ & $48 \mathrm{~h}$ & $72 \mathrm{~h}$ \\
\hline Lote & \multicolumn{8}{|c|}{ - } \\
\hline 1 & $94 \mathrm{a}$ & $96 a$ & $92 \mathrm{a}^{*}$ & $94 \mathrm{a}$ & $95 \mathrm{a}$ & $93 \mathrm{a}$ & $95 \mathrm{a}^{*}$ & $93 \mathrm{a}$ \\
\hline 2 & $85 b$ & $91 a b$ & $83 b$ & $88 a b$ & $90 a b$ & $91 \mathrm{ab}$ & $90 a b$ & $88 a b$ \\
\hline 3 & $77 \mathrm{~b}$ & $77 c$ & $71 \mathrm{c}$ & $78 \mathrm{c}$ & $79 b$ & $78 \mathrm{c}$ & $73 c$ & $71 \mathrm{c}$ \\
\hline 4 & $92 \mathrm{a}$ & $86 \mathrm{bc}$ & $92 \mathrm{a}$ & $92 \mathrm{a}$ & $93 a$ & $92 a b$ & $86 b$ & $87 a b$ \\
\hline 5 & $82 b$ & 85 bc & 77 bc & 82 bc & $80 \mathrm{~b}$ & $84 \mathrm{bc}$ & $85 \mathrm{bc}$ & $83 \mathrm{bc}$ \\
\hline C.V.(\%) & \multicolumn{4}{|c|}{4,73} & \multicolumn{4}{|c|}{5,22} \\
\hline
\end{tabular}

*Comparação de médias em cada coluna, pelo teste de Tukey a $5 \%$.

TABELA 7 - Dados médios de grau de umidade obtidos após os períodos de envelhecimento acelerado (procedimento tradicional e com solução salina) de sementes de cinco lotes de tomate, híbrido Bruna.

\begin{tabular}{|c|c|c|c|c|c|c|c|c|}
\hline \multirow[t]{3}{*}{$\begin{array}{l}\text { Hibrido } \\
\text { Bruna }\end{array}$} & \multicolumn{4}{|c|}{$\begin{array}{c}\text { Envelhecimento acelerado } \\
\text { (tradicional) }\end{array}$} & \multicolumn{4}{|c|}{$\begin{array}{c}\text { Envelhecimento acelerado } \\
\text { (com solução salina) }\end{array}$} \\
\hline & \multicolumn{2}{|c|}{$38^{\circ} \mathrm{C}$} & \multicolumn{2}{|c|}{$41^{\circ} \mathrm{C}$} & \multicolumn{2}{|c|}{$38^{\circ} \mathrm{C}$} & \multicolumn{2}{|c|}{$41^{\circ} \mathrm{C}$} \\
\hline & $48 \mathrm{~h}$ & $72 \mathrm{~h}$ & $48 \mathrm{~h}$ & $72 \mathrm{~h}$ & $48 \mathrm{~h}$ & $72 \mathrm{~h}$ & $48 \mathrm{~h}$ & $72 \mathrm{~h}$ \\
\hline Lote & - & - & -1-- & - & - \% ------ & - & 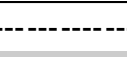 & - \\
\hline 1 & 37,5 & 38,1 & 38,4 & 39,9 & 9,2 & 9,8 & 9,6 & 10,2 \\
\hline 2 & 35,6 & 37,2 & 37,6 & 38,3 & 9,4 & 10,0 & 9,2 & 9,9 \\
\hline 3 & 35,1 & 36,4 & 36,5 & 37,8 & 10,1 & 10,4 & 10,2 & 10,6 \\
\hline 4 & 35,7 & 37,9 & 37,1 & 38,8 & 9,4 & 9,9 & 9,1 & 10,0 \\
\hline 5 & 36,2 & 37,8 & 37,9 & 38,1 & 9,5 & 10,1 & 9,6 & 10,4 \\
\hline
\end{tabular}


TABELA 8 - Dados médios obtidos para o teste de deterioração controlada e para o grau de umidade após os períodos de condicionamento, de sementes de cinco lotes de tomate, híbrido Bruna.

\begin{tabular}{|c|c|c|c|c|c|c|c|c|c|c|c|c|}
\hline \multirow{3}{*}{$\begin{array}{l}\text { Hibrido } \\
\text { Bruna }\end{array}$} & \multicolumn{6}{|c|}{ Deterioração controlada } & \multicolumn{6}{|c|}{ Grau de umidade após deterioração controlada } \\
\hline & \multicolumn{3}{|c|}{$24 \mathrm{~h}$} & \multicolumn{3}{|c|}{$48 \mathrm{~h}$} & \multicolumn{3}{|c|}{$24 \mathrm{~h}$} & \multicolumn{3}{|c|}{$48 \mathrm{~h}$} \\
\hline & $19 \%$ & $21 \%$ & $24 \%$ & $19 \%$ & $21 \%$ & $24 \%$ & $19 \%$ & $21 \%$ & $24 \%$ & $19 \%$ & $21 \%$ & $24 \%$ \\
\hline Lote & \multicolumn{12}{|c|}{ - } \\
\hline 1 & $90 \mathrm{a}^{*}$ & $90 \mathrm{a}$ & 94 a & 93 a & $91 \mathrm{a}$ & $91 \mathrm{a}$ & 19,4 & 20,8 & 23,7 & 19,4 & 21,2 & 23,7 \\
\hline 2 & $88 \mathrm{a}$ & $89 a$ & $92 a b$ & $91 \mathrm{ab}$ & $87 a$ & $87 a$ & 18,7 & 21,0 & 23,6 & 18,7 & 20,8 & 23,9 \\
\hline 3 & $71 \mathrm{~b}$ & $67 \mathrm{~b}$ & $78 \mathrm{c}$ & $66 c$ & $75 \mathrm{~b}$ & $67 \mathrm{~b}$ & 19,0 & 21,0 & 23,9 & 19,4 & 21,3 & 24,2 \\
\hline 4 & $92 \mathrm{a}$ & $89 a$ & $93 \mathrm{a}$ & $92 \mathrm{a}$ & $89 a$ & 86 a & 18,8 & 21,2 & 23,8 & 19,3 & 21,7 & 23,9 \\
\hline 5 & 89 a & $87 \mathrm{a}$ & $83 b c$ & $83 \mathrm{~b}$ & $75 \mathrm{~b}$ & $87 \mathrm{a}$ & 19,3 & 20,9 & 23,8 & 18,7 & 20,8 & 24,4 \\
\hline C.V.(\%) & \multicolumn{12}{|c|}{4,68} \\
\hline
\end{tabular}

${ }^{*}$ Comparação de médias em cada coluna, pelo teste de Tukey a $5 \%$.

Diante do exposto, verificou-se que, para os dois híbridos, a combinação $41^{\circ} \mathrm{C} / 72$ horas de condicionamento foi a mais eficiente para realização do teste de envelhecimento acelerado, proporcionando a separação adequada dos lotes em níveis de vigor e fornecendo informações compatíveis com os resultados dos testes de germinação e emergência de plântulas em casa de vegetação. Os resultados obtidos estão, ainda, de acordo com International Seed Testing Association (1995), que recomendou a mesma combinação para condução do teste com sementes de tomate. As combinações com a utilização da temperatura de $38^{\circ} \mathrm{C}$ revelaram resultados menos consistentes quanto à identificação dos lotes de menor potencial fisiológico, especialmente para o híbrido Bruna. No caso do teste de deterioração controlada, constatou-se que o período de 24 horas em banho-maria e sementes com $24 \%$ de água mostrou ser o indicador de potencial fisiológico mais eficiente.

\section{CONCLUSÕES}

No teste de envelhecimento acelerado (procedimento tradicional e com solução salina), o período de condicionamento de 72 horas, a $41^{\circ} \mathrm{C}$, apresenta sensibilidade suficiente para avaliação do potencial fisiológico das sementes;

No teste de deterioração controlada, a combinação $24 \%$ de água, durante 24 horas em banhomaria, a $45^{\circ} \mathrm{C}$, é eficiente para detectar diferenças de vigor entre os lotes.

\section{REFERÊNCIAS BIBLIOGRÁFICAS}

BENNETT, M.A.; BARR, A.J.; GRASSBAUGH, E.M.; EVANS, A.F. Seed vigor evaluation of su, se and sh2 sweet corn genotypes using the saturated salt accelerated aging (SSAA) test. In: CONGRESS OF ISTA, 25., Pretoria, 1998. Abstracts. Pretoria, 1998. p.92-93.
BRASIL. Ministério da Agricultura. Regras para análise de sementes. Brasília: SNDA, DNDV, CLAV, 1992. 365p.

DELOUCHE, J.C.; BASKIN, C.C. Accelerated aging techniques for predicting the relative storability of seed lots. Seed Science and Technology, v.1, p.427-452, 1973.

INTERNATIONAL SEED TESTING ASSOCIATION. Handbook of vigour test methods. 3.ed. Zürich: ISTA, 1995. 117p.

JIANHUA, Z.; McDONALD, M.B. The saturated salt accelerated aging test for small-seeded crops. Seed Science and Technology, v.25, p.123-131, 1996.

LOEFFLER, T.M.; TEKRONY, D.M.; EGLI, D.B. The bulk conductivity test as an indicator of soybean seed quality. Journal of Seed Technology, v.12, p.37-53, 1988.

MARCOS FILHO, J. Testes de vigor: importância e utilização. In: KRZYZANOWSKI, F.C.; VIEIRA, R.D.; FRANÇA NETO, J.B. (Ed.) Vigor de sementes: conceitos e testes. Londrina: ABRATES, 1999a. cap.1, p.1-21.

MARCOS FILHO, J. Teste de envelhecimento acelerado. In: KRZYZANOWSKI, F.C.; VIEIRA, R.D.; FRANÇA NETO, J.B. (Ed.) Vigor de sementes: conceitos e testes. Londrina: ABRATES, 1999b. cap.3, p.1-24.

MARCOS FILHO, J.M.; CICERO, S.M.; SILVA, W.R. Avaliação da qualidade das sementes. Piracicaba: FEALQ, 1987. 230p.

PANOBIANCO, M.; MARCOS FILHO, J. Comparação entre métodos para avaliação da qualidade fisiológica de sementes de pimentão. Revista Brasileira de Sementes, v.20, p.306310, 1998.

POWELL, A.A. The controlled deterioration test. In: van de VENTER, H.A. (Ed.) Seed vigour testing seminar. Copenhagen: ISTA, 1995. p.73-87.

RODO, A.B.; PANOBIANCO, M.; MARCOS FILHO, J. Metodologia alternativa do teste de envelhecimento acelerado para sementes de cenoura. Scientia Agricola, v.57, p.289292, 2000.

ROSSETTO, C.A.V.; FERNANDEZ, E.M.; MARCOS FILHO, J. Metodologias de ajuste do grau de umidade e comportamento das sementes de soja no teste de germinação. Revista Brasileira de Sementes, v.17, p.171-178, 1995.

ZONTA, E.P.; MACHADO, A.A. Sistema de análise estatística para microcomputadores - SANEST. Pelotas: UFPel, 1984. 109p.

$\overline{\text { Recebido em 21 }} .08 .00$ 